\title{
THE IMPACT OF ISOLATED OLIGOHYDRAMNIAS AT TERM ON PERINATAL OUTCOME: A COMPARATIVE STUDY
}

\author{
Nadia Arif, Bushra Zafar*, Ayesha Arif**, Raja Qaseem Ahmed, Farrukh Shehzad* \\ Combined Military Hospital Okara/National University of Medical Sciences (NUMS) Pakistan, *Pak Emirates Military Hospital/National University of Medical \\ Sciences (NUMS) Rawalpindi Pakistan, ${ }^{* *}$ Combined Military Hospital Murree/National University of Medical Sciences (NUMS) Pakistan
}

\section{ABSTRACT}

Objective: To study the impact of isolated oligohydramnios at term on mode of delivery and perinatal outcome.

Study Design: Prospective comparative study.

Place and Duration of Study: Combined Military Hospital Okara, from Aug 2019 to Aug 2020.

Methodology: A total of 250 patients were recruited in the study. They were divided in 2 groups. In group A there was 123 patients, with isolated oligohydramnias at term, amniotic fluid index of $\leq 5 \mathrm{~cm}$, while in group B 127 patients, with normal liquor volume were included through lottery method. Demographic parameters, Intrauterine fetal demise, mode of delivery, perinatal out comes like meconium stained amniotic fluid, low birth weight, APGAR score at 1 and 5 minutes, of two groups were compared.

Results: A total of $57(46.3 \%)$ patients in group A delivered through cesarean section and 27 (21.3\%) in group B. Meconium staining of liquor was in $56(45.5 \%)$ in group A versus $13(10.2 \%)$ in group B. As compared to group B the patients in group A lower birth weight babies $2.6 \pm 0.34 \mathrm{~kg}$ versus $3.0 \pm 0.33 \mathrm{~kg}$ were delivered. Mortality in group A, intrauterine fetal demise was $4(3.3 \%)$ and still birth was $2.3 \%$. There were no perinatal mortality in controlled group B.

Conclusion: Isolated oligohydramnias at term is not associated with adverse perinatal outcome. Umbilical cord compression, potential utero-placental insuffiency and increased incidence of meconium stained liquor possibly explains the increased perinatal morbidity. The delivery should be routinely advocated as in otherwise uncomplicated pregnancy with appropriately grown fetus.

Keywords: Cesarean section, Meconium stained liquor, Oligohydramnias, Perinatal outcome.

This is an Open Access article distributed under the terms of the Creative Commons Attribution License (https://creativecommons.org/licenses/by-nc/4.0/), which permits unrestricted use, distribution, and reproduction in any medium, provided the original work is properly cited.

\section{INTRODUCTION}

Amniotic fluid is collected within the amniotic cavity. It surrounds and protects the developing embryo. It helps to facilitate the exchange of nutrients, biochemical products and water between mother and the fetus. Before 16 weeks of gestation it is the transudate of maternal circulation. Fetal urine is the major contributor of the amniotic fluid in the latter half of pregnancy. Fetal respiratory tract secretions also contribute to amniotic fluid production ${ }^{1}$. Normal amniotic fluid volume is essential for adequate fetal growth and development ${ }^{2}$. It allows fetal movement, musculoskeletal development as well as protection from infections. Amniotic fluid volume can be measured on ultrasound examination of fetus, most commonly used method is amniotic fluid index evaluation (AFI) ${ }^{3}$, measured as sum of amniotic fluid volume measured from all 4 quadrants around the fetus. Amniotic fluid index was described by Phelan ${ }^{4}$.

Oligohydramnios is defined as AFI $<5 \mathrm{~cm}$ or below the fifth percentile to estimate the amniotic fluid

Correspondence: Dr Bushra Zafar, Consultant Gynaecologist, Pak Emirates Military Hospital, Rawalpindi Pakistan

Received: 17 Aug 2020; revised received: 13 Oct 2020; accepted: 21 Oct 2020 volume $^{5}$. Rate of oligohydramnios has been reported to be $0.5-8 \%{ }^{6}$, while when associated with fetal anomalies the incidence may be as high as $37 \%^{7}$. Oligohydramnias is associated with cord compression and placental dysfunction leading to impaired blood supply to the growing fetus. This is one of the major risk for perinatal morbidity and mortality associated with this condition. Oligohydramnios may result in fetal complications like fetal cord compression, utero-placental insufficiency, pulmonary hypoplasia and meconium aspiration syndrome ${ }^{8}$. These complications lead to increased perinatal morbidity and mortality. Increased risk for fetal- distress, and neonatal intensive care admissions due to APGAR scores $\leq 7$ and meconium aspiration syndrome ${ }^{9}$.

In our country there are limited resources for frequent pregnancy follow up visits and continuous non invasive and invasive fetal monitoring tools like fetal scalp PH monitoring electrodes during labour. This contributes to increasing cesarean section rate and frequent neonatal admissions to intensive care units ${ }^{10}$. The objective of our study was to assess the impact of isolated oligohydramnios at term, on time (gestational age) and mode of delivery and perinatal outcome. 


\section{METHODOLOGY}

This prospective comparative study was conducted at Combined Military Hospital Okara from August 2019 to August 2020. After approval from hospital ethics committee (IERC/OBS/2020/04), assuming 37\% prevalence of isolated oligohydramnias with a $80 \%$ power and a $4 \%$ margin of error, 250 patients were included in study through non probability convenience sampling ${ }^{13}$. Sample size was calculated using WHO sample size calculator. These patients were divided in 2 groups. In group A $(n=123)$ isolated oligohydramnios that is AFI $\leq 5$ on ultrasound scan at or after 37 weeks of gestation. Group B ( $n=127)$ with normal liquor volume at term which is 37 weeks of gestation. All booked patients at or before 20 weeks of gestation with an uncomplicated pregnancy and did not have any associated medical illness. Patients with history of medical illness like pregnancy induced hypertension (PIH), diabetes, multiple pregnancies, intra uterine growth restriction (IUGR), congenital abnormalities, pre mature rupture of membranes ( PROM), previous history of pre term delivery were excluded from the study. Data was recorded on pre designed performa, which included demographic and clinical details of each patient. Demographic parameters, Intrauterine fetal demise, mode of delivery, perinatal out comes like meconium stained amniotic fluid, reduced birth weight, APGAR score at 1 and 5 minutes, of two groups were compared.

Data was analyzed using SPSS-22. Mean and standard deviation were calculated for quantitative variables, frequency and percentages were calculated for qualitative variables. Independent sample t-test was applied to assess quantitative variable and chi square test was used to compare the qualitative variables. The $p$-value $\leq 0.05$ was taken statistically significant.

\section{RESULT}

During one year study time 250 patients were recruited in the study, out of these 123 had isolated oligohydramnias and were referred as group A. The control group B had 127 participants. The frequency of oligohydramnias was found to be $49 \%$ in this group of population under study.

Demographic data is shown in table-I. Mode of delivery in group A was cesarean section in 57 (46.3\%) while in group B $27(21.3 \%)$ underwent cesarean section, table-II. This higher operative delivery rate showed low threshold for early intervention in group A. Meconium staining of liquor was in $56(45.5 \%)$ in group A and 13 (10.2\%) in group B.
As compared to group B the patients in group A lower birth weight babies $2.6 \pm 0.34 \mathrm{~kg}$ as compared $3.0 \pm 0.33 \mathrm{~kg}$ were delivered, mainly due to delivery at earlier gestation mean $37+3 \pm 1.22$ weeks as compared mean $38+5 \pm 1.08$ weeks in group B. Mortality in group A, intrauterine fetal demise was $4(3.3 \%)$ and still birth was $2.3 \%$. There were no perinatal mortality in controlled group $B$.

Table-I: Demographic details of patients in both groups.

\begin{tabular}{l|c|c}
\hline & Group A & Group B \\
\hline $\begin{array}{l}\text { Maternal Age (years) } \\
\text { mean } \pm \text { SD }\end{array}$ & $23.76 \pm 2.7$ & $23.98 \pm 3.2$ \\
\hline $\begin{array}{l}\text { Gestational Age } \\
\text { (weeks) mean } \pm \text { SD }\end{array}$ & $37.3 \pm 1.22$ & $38.55 \pm 1.08$ \\
\hline
\end{tabular}

Table-II: Comparison of caesarean section rate in both groups.

\begin{tabular}{l|c|c|c}
\hline & $\begin{array}{c}\text { Group A } \\
\text { n (\%) }\end{array}$ & $\begin{array}{c}\text { Group B } \\
\text { n (\%) }\end{array}$ & $\begin{array}{c}p- \\
\text { value }\end{array}$ \\
\hline Cesarean Section & $57(46.3 \%)$ & $27(21.3 \%)$ & \multirow{2}{*}{$<0.001$} \\
\cline { 1 - 2 } $\begin{array}{l}\text { Spontaneous } \\
\text { vaginal delivery }\end{array}$ & $66(53.7 \%)$ & $100(78.7 \%)$ & \\
\cline { 1 - 3 }
\end{tabular}

Table-III: Perinatal morbidity in both groups regarding the perinatal morbidity and mortality in both groups the difference in apgar score at 1 and 5 minutes and NICU admission.

\begin{tabular}{l|c|c|c|c}
\hline & & $\begin{array}{c}\text { Group } \\
\text { A }\end{array}$ & $\begin{array}{c}\text { Group } \\
\text { B }\end{array}$ & $\begin{array}{c}p \text { - } \\
\text { value }\end{array}$ \\
\hline \multirow{3}{*}{$\begin{array}{l}\text { Apgar Score } \\
\text { (Mean } \pm \text { SD) }\end{array}$} & 1 & $7 \pm$ & $7.7 \pm$ & \\
\cline { 2 - 4 } & Minute & 0.86 & 0.96 & \multirow{2}{*}{$<0.05$} \\
\cline { 2 - 4 } & Minute & $\begin{array}{c}7.6 \pm \\
0.90\end{array}$ & $\begin{array}{c}8.5 \pm \\
0.5\end{array}$ & \\
$\begin{array}{l}\text { Neonatal intensive } \\
\text { Care Unit }\end{array}$ & & 15 & 14 & \multirow{2}{*}{0.26} \\
Admission, n (\%) & & $(19 \%)$ & $(18 \%)$ & \\
\hline
\end{tabular}

\section{DISCUSSION}

Assessment of amniotic fluid volume is integral part of fetal surveillance during antenatal period ${ }^{11}$. Many study have proved that oligohydramnias increases the risk of perinatal morbidity and mortality. Due to easier access to ultrasonography more cases of oligohydramnias are being identified now a days ${ }^{12}$. This study has shown that pregnancies complicated with isolated oligohydramnias at term do not show increased perinatal morbidity.

Demographic details were comparable in both groups. Majority of patients were between age group 20-32 years in both groups. We found no substantial difference in demographic details among women of both groups. Frequency of oligohydramnias in our population was $49 \%$ compared to study conducted by Donald, in his study it was $60 \%{ }^{12}$. The cesarean section 
rate was high $46.3 \%$ in group A and in controlled group it was $21.3 \%$, this is comparable to a study conducted by Ahmed et al in Karachi, her study revealed the cesarean section rate to be $42 \%$ in patients with oligohydramnias and $18 \%$ in control group ${ }^{13}$. The cesarean section rate was $72.6 \%$ in a study conducted by Siraj $^{14}$. This higher cesarean section rate demonstrates low threshold for cesarean sections among obstetrician in oligohydramnias group. The various findings in our study are comparable to results of similar studies done in Pakistan and abroad.

In our study meconium staining of amniotic fluid was $56(45.5 \%)$ as compared to study conducted by Chate P it was $23(46 \%) p$-value $0.001^{15}$. The APGAR score of babies at 1 and 5 minutes in group A patients was $7 \pm 0.86$ and $7.7 \pm 0.96$ and in group $B$ it was $7.6 \pm$ 0.90 and $8.5 \pm 0.5$.it is comparable to study conducted by Sreelakshmi U, in which it was $<7$ in $34 \%$ of patients at 1 minute and $<7$ in $25 \%$ of patients at 5 minutes. NICU admission was $19 \%, p$-value 0.26 in our study in group A and in group B it was $18 \%$ as compared to $23 \%, p$-value 0.212 in other study ${ }^{16}$. In our study the rate of intra uterine fetal demise was 3.3\% and still birth was $2.3 \%$ as compared to study by Moses $\mathrm{V}$ in which it was $3 \%{ }^{17}$. The Intra uterine fetal demise in a study by Gosh et al is $5.5 \% 18$.

A multi country, randomized cluster trial conducted by Figueroa in the rural areas of Guatemala, Pakistan, Zambia, Kenya and Demographic republic of Congo (DRC) found rate of oligohydramnias to be 1.5 times higher in Pakistan and lowest rates were recorded in Zambia n Congo ${ }^{19}$. Although limited data from local studies is available regarding etiology, effects and outcome of pregnancies effected with oligohydramnias. Mean birth weight in patients with oligohydramnias was 2.7 kilogram in patients with oligohydramnias and 2.97 in control group ${ }^{19}$, as compared in our study mean birth weight was 2.6 kilogram in group A. The study also revealed that isolated oligohydramnias is associated with iatrogenic preterm deliveries, 31 weeks and comparably low birth weight in contrast to it the mean gestation in patients with oligohydramnias was $37 \pm 3$ weeks in our study.

An amniotic fluid index of $\leq 5 \mathrm{~cm}$ detected at term is not associated with poor perinatal outcome. Its association with raised cesarean section rate is due to early intervention done for non reactive cardiotocograph (CTG) and fetal distress.

Hence, our study revealed that isolated oligohydramnias is not associated with adverse perinatal out- come. These results strongly co relate with a large multi-center clinical trial of Routine Antenatal Diagnostic Imaging with Ultrasound (RADIUS).

\section{LIMITATIONS IN STUDY}

The sample size doesn't provide enough data to determine the optimal timing of delivery in patients with oligohydramnias. It was a hospital based study and doesn't represent the data of whole population.

\section{CONCLUSION}

Now a days oligohydramnias is frequently seen in obstetrics patients. Isolated oligohydramnias at term is not associated with adverse perinatal outcome. Umbilical cord compression, potential utero-placental insuffiency and increased incidence of meconium stained liquor possibly explains the increased perinatal morbidity. The delivery should be routinely advocated as in otherwise uncomplicated pregnancy with appropriately grown fetus. High cesarean section rate is due to early intervention and due to obstetrician's own choice.

\section{CONFLICT OF INTEREST}

This study has no conflict of interest to be declared by any author.

\section{REFERENCES}

1. Tamblyn JA, Morris RK. Aberrant liquor volume. Obstetrics and Gynecology, An Evidence based text for MRCOG, 3rd edition. Luesl DM, Kilby 2015; 1(1): 292-99.

2. Sreelakshmi U, Bindu T, Subhashini T, Impact of oligohydramnios on maternal perinatal outcome: a comparative study, Int J Reprod contracept obstet gynecol 2018; 7(8): 3205-10.

3. Rutherford SE, Phelan JP, Smith CV, Jacobs N. The four-quadrant assessment of amniotic fluid volume: an adjunct to antepartum fetal heart rate testing. Obstet Gynecol 1987; 70(3): 353-56.

4. Moore TR. Clinical assessment of amniotic fluid. Clin Obstet Gynecol. Lippincott-Raven Publishers 1997; 40(2): 302-13.

5. Locatellia A, Zagarella A, Toso L, Assi F, Ghidini A, Biffi A. Serial assessment of amniotic fluid index in uncomplicated term pregnancies: Prognostic value of amniotic fluid reduction. J Matern Neonatal Med 2004: 15(2): 233-36.

6. Han CS. Fetal Biophysical Profile. Obstet Imaging Fetal Diagnosis Care 2018; 9(1): 537-40.

7. Coady AM. Amniotic Fluid. Twining's Text book Fetal Abnorm. Churchill Living Stone 2015; 2(2): 81-99.

8. Morris R. Melter CH, Tamblyn J. Association and prediction of amniotic fluyid measurements of adverse pregnancy out comes: systematic review and meta-anaylsis. BJOG 2014; 121 (6): 686-99.

9. Ali HS. Assessment of amniotic fluid index in normal pregnancy at a tertiary care hospital setting. Dept of Obstet and Gyne, Ziaud-Din University, Karachi, Pakistan. JAMC 2009; 21(3): 149-50.

10. Goldenberg RL, Nathan R, Swanson D, Saleem S, Mirza W, Esamai $\mathrm{F}$, et al. Routine antenatal ultrasound in low and middle income countries: first look-a cluster randomized trial. BJOG 2018; 125(4): 1591-99.

11. Mathuriya G, Verma M, Rajpoot S. Comparative study of maternal and fetal outcome between low and normal amniotic 
fluid index at term. Int J Reprod Contracept Obstet Gynecol 2017; 6(2): 640-44.

12. Donald DM. pregnancy outcomes after antepartum diagnosis of oligohydramnias at or beyond 34 weeks of gestation. Am J Obstet Gynecol 2000; 182(4): 909-12.

13. Ahmad H, Munim S. Isolated oligohydramnios is not an indicator for adverse perinatal outcome. JPMA 2019; 59(2): 691-3.

14. Siraj A, Baqai S, Naseer S, Raja A. The effect of uncomplicated oligohydramnias on perinatal outcome. Pak Armed Forces Med J 2016; 66(3): 333-36.

15. Chate P, Khatri M, Hariharan C. Pregnancy outcome after diagnosis of oligohydramnias at term. Int J Reprod Contracept Obstet Gynecol 2013; 2(1): 23-26.

16. Sreelakshmi U, Bindu T, Subhashini T. Impact of oligohydramnias on maternal and perinatal outcome: a comparative study. Int
J Reprod Contracept Obstet Gynecol2018; 7(8): 3205-10.

17. Moses V, Thakre S. A study of Maternal and fetal outcome in third trimester diagnosed case of oligohydramnias.Int J Reprod contracept obstet Gynecol 2016; 5(9): 2944-48.

18. Gaosh R, Oza H, Pabhiyar B. Maternal and fetal outcome in oligohydramnias: study from a tertiary care hospital, Ahmedabad, India. Int J Reprod Contracept Obstet Gynecol 2018; 7(3): 907-10.

19. Figueroa L, Mc Clure EM, Swanson J, Nathan R, Garces AL, Moore JL. Oligohydramnias: a prospective study of fetal, neonatal and maternal outcomes in low - middle income countries. Reproductive Health 2020; 17(19): 2-7.

20. Zhang J, Troendle J, Meikle S, Klebanoff MA, Rayburn WF. Isolated oligohydramnias is not associated with adverse perinatal outcomes. BJOG 2004; 111(2): 220-5. 